\title{
Reconciling Conflicting Paradigms of Biodiversity Conservation: Human Intervention and Rewilding
}

\author{
KOENRAAD VAN MEERBEEK, BART MUYS, SIMON D. SCHOWANEK, AND JENS-CHRISTIAN SVENNING
}

\begin{abstract}
There are strong opposing views among conservationists about whether we have to intervene to safeguard our natural heritage or not. In the Western European tradition, human intervention has been dominating, whereas, elsewhere, rewilding aimed at restoring self-regulating ecosystems has often been preferred. However, cultural rather than ecological differences are at the root of these opposing paradigms, leading to management strategies that are not always optimal for biodiversity conservation. In the present article, we propose a framework based on the relationship between ecosystem dynamics and the human footprint, including land-use legacies, to guide the mixture of rewilding and intervention practices in order to ensure a biodiverse future. We argue that these paradigms are not conflicting but complementary and advocate for rewilding where possible, human intervention where needed.
\end{abstract}

Keywords: alternative stable states, biodiversity loss, ecosystem states, nature conservation, wilderness

A cross the globe, landscapes have been shaped by a long history of human presence, which has disrupted natural processes and ecosystem dynamics that drive diversity patterns. However, moderate anthropogenic disturbances have also created or preserved landscape mosaics in many parts of the world, offering opportunities for disturbance-dependent species. European seminatural grasslands (Halada et al. 2011, Feurdean et al. 2018), traditional Satoyama landscapes in Japan (Normile 2016), and fire-stick farming savannah woodlands in Australia (Bird and Nimmo 2018) are examples of ecosystems that have been maintained by or resulted from traditional land-use practices. Although sometimes very distinct from the natural situation, these human-modified landscapes may have high cultural and ecological value.

The role of humans in shaping European landscapes was recognized decades ago and is widely accepted in European conservation thinking. For example, the European Union promotes the preservation of traditional farming practices to manage landscapes, using agri-environment schemes and other environmental policies (Fischer et al. 2012). As a result, European conservationists apply management interventions such as mowing, coppicing, and stock grazing in an attempt to maintain intermediate levels of disturbance to preserve both biodiversity and cultural landscapes (Halada et al. 2011). Although sustainable management of the ecosystem ensured long-term provision of resources in most traditional farming systems, financial-reward-based conservation lacks an inherent incentive and is sensitive to shifts in politics and socioeconomic drivers (Fischer et al. 2012). In contrast to the mainly Western European interventionist view on conservation, many other parts of the world have a dualistic view of culture and nature, although the notion that people had important functional roles in past and present ecosystems is getting wider global support (e.g., Australia: Bird and Nimmo 2018). As a result, human disturbances are, in general, regarded as a threat to the environment (Queiroz et al. 2014). The focus of nature conservation is therefore on protecting or restoring natural areas, which are seen as the pristine state of the environment (Sutherland 2002, Boitani and Sutherland 2015). Conservation efforts are framed by the idea that there are still untouched wild areas left or that humankind only recently modified these landscapes. Therefore, they can easily be restored to some "original" state. This view neglects the substantial influence of people on ecosystems for millennia in many parts of the world (Boitani and Sutherland 2015).

The question of whether to intervene for conservation purposes is not new and has been discussed for several decades. In Europe, recent land-use dynamics have sparked the debate again among academics and conservation managers (Pereira and Navarro 2015, Nogués-Bravo et al. 2016). The ongoing farmland abandonment in response to socioeconomic trends is considered a big challenge for biodiversity conservation. There is evidence that the cessation of traditional practices will lead to the loss of local disturbance 


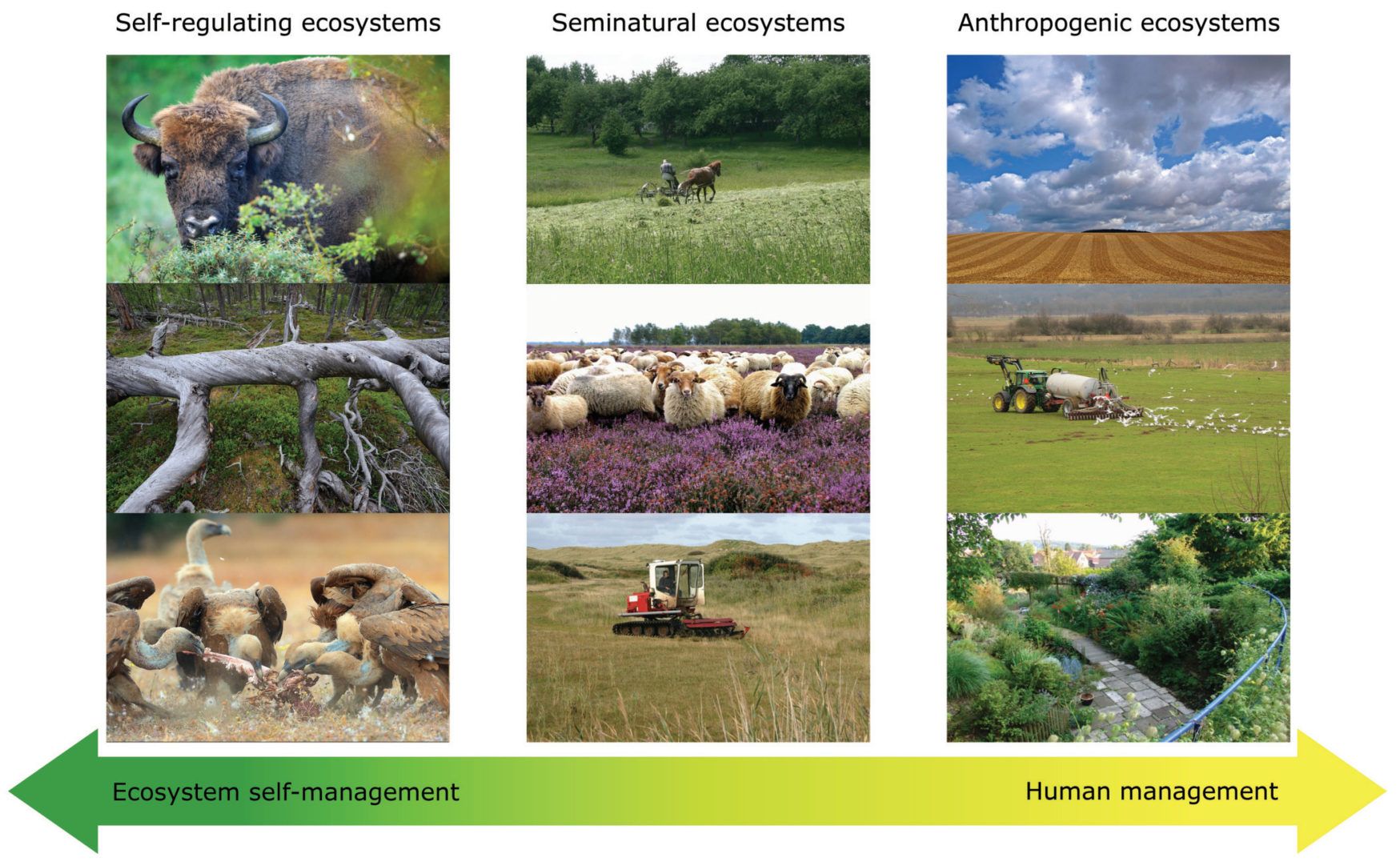

Figure 1. Three ecosystem states along the management continuum, a gradient from human management to ecosystem selfmanagement. Self-regulating ecosystems: natural processes and disturbances such as fire, flooding or trophic cascades are the main drivers of ecosystem dynamics. Seminatural ecosystems: species composition and ecosystem functioning are, to a limited extent, influenced by human activities. Anthropogenic ecosystems: abiotic and biotic conditions have been strongly altered by human activities. Note that these ecosystem states refer not to a certain vegetation type but to differences in processes driving ecosystem dynamics. Photographs: Rewilding Europe/Staffan Widstrand, Saxifraga/Hans Boll, Hans Dekker and Harry van Oosterhout and Martin Hermy.

regimes and associated biodiversity (Halada et al. 2011, Boitani and Sutherland 2015). Many conservationists stress the importance of intermediate human disturbances and advocate countering land abandonment by stimulating traditional farming practices (Halada et al. 2011).

Others view the land-use changes as an opportunity to restore self-regulating ecosystems and put rewilding forward as an alternative conservation strategy on these marginal lands (Pereira and Navarro 2015). Rewilding has varied interpretations and versions in the literature (Corlett 2016, Svenning et al. 2016). In the present article, we see rewilding as a subcategory of ecological restoration and define it broadly as a type of ecological restoration aiming to (partially) restore self-sustaining and complex ecosystems via restoring natural ecological processes while minimizing human interventions (Perino et al. 2019). With the rise of the rewilding movement, the call for wilder, self-regulating ecosystems has been louder than ever before (Fernández et al. 2017). However, simultaneously, the notion that rapid environmental change needs to be countered by active human intervention is growing worldwide (Hobbs et al. 2011, Corlett 2016).
These opposing views are not solely based on ecological differences or different land-use histories (Boitani and Sutherland 2015) but are also strongly culturally defined and depend on prevalent values and beliefs about nature (Sutherland 2002, Queiroz et al. 2014). The debate about rewilding versus management is therefore often dominated by opinions (Svenning et al. 2016). As the relationship between people and nature shapes regional environmental policies (Queiroz et al. 2014), this may lead to management strategies that are not always beneficial for biodiversity. In addition, the current literature largely fails to integrate the merits and pitfalls of both views and is therefore often unsuccessful in providing proper guidance for if, when, and how to intervene. We argue that these paradigms need not be conflicting but are complementary ecosystem management strategies along a gradient from human management to ecosystem self-management (figure 1). In the present article, we integrate existing conservation strategies into a new framework. First, we combine concepts from natural disturbance ecology with the alternative stable states theory to explain how human pressure on ecosystem dynamics gives 


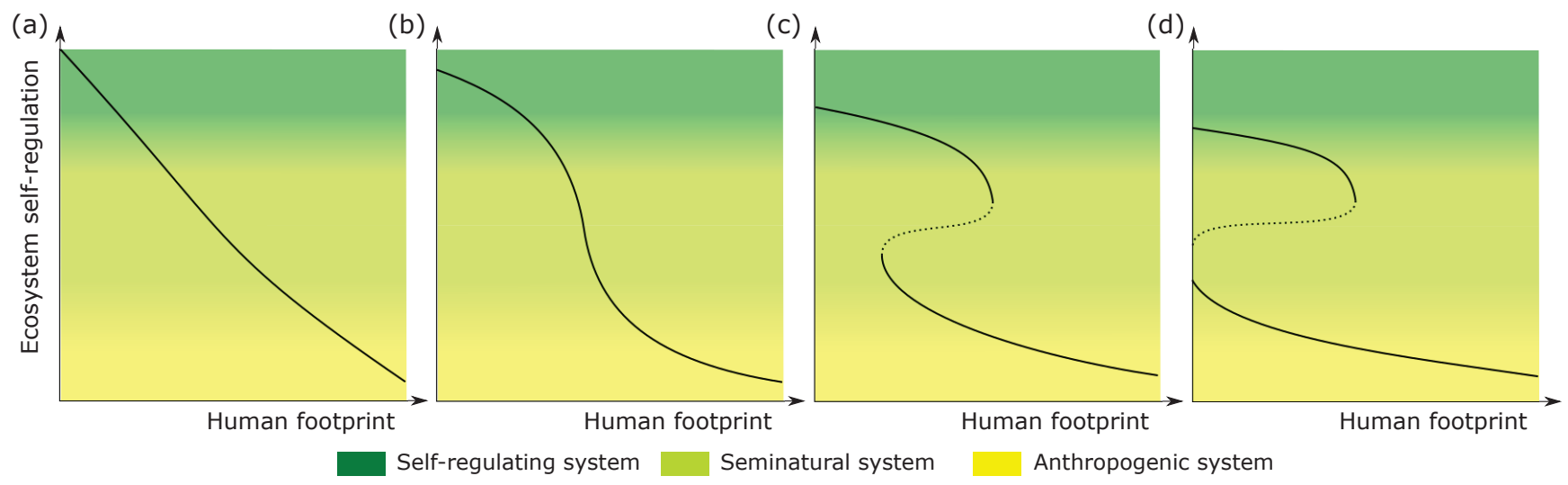

Figure 2. Ecosystem state curves show different relationships between human footprint and ecosystem self-regulation. The colors correspond to the management continuum from low to high ecosystem self-regulation (y-axis), the black lines are possible ecosystem state trajectories. (a) Small-scale and short-term human disturbances cause a gradual change in ecosystem state. (b) Pervasive human footprints could affect the shape of the curve to a threshold or (c) even induce hysteresis. (d) Finally, in totally degraded ecosystems, the complete self-regulated state cannot be restored anymore. Species-rich ecosystems can occur in each ecosystem state.

rise to different ecosystem states. Then, we complete this framework with practical guidelines to direct conservation actions along the management spectrum. Our work extends previous research on ecosystem thresholds and alternative stable states theory in restoration ecology (Suding et al. 2004, Suding and Hobbs 2009) and is focused on how the degradation cascade from self-regulating to anthropogenic ecosystems and the possible irreversible nature of this process influences management decisions. With the accelerating environmental change and the increasing probability of a noanalog future, the emphasis in the present article is not on specific species or habitats but on ecosystem functionality.

\section{The human footprint and ecosystem states}

Natural disturbances are an important component of natural systems and generate a substantial part of the observed ecological dynamics. However, anthropogenic activities have globally increasing impacts on the environment (Venter et al. 2016), thereby altering the structure and function of ecosystems and disrupting natural disturbance regimes. One could conceptualize the trade-off between natural processes and human disturbances as three ecosystem states, which can be distinguished by the type of processes driving ecosystem dynamics (figure 1). Ecological and socioecological feedback mechanisms stabilize ecosystems in a certain state. In selfregulating ecosystems, containing both (near-) natural and restored ecosystems, natural processes play a major role in ecosystem structure and function. Seminatural ecosystems are, to a limited extent, influenced by human activities. Species composition is largely shaped by but not directly controlled by human action. However, species and habitats do require recurring intermediate human(-governed) disturbances, because some natural disturbances are lost (e.g., the loss of megaherbivores). Furthermore, increasing the human footprint degrades the ecosystem to an anthropogenic state, where socioeconomic factors and human structures act as stabilizing factors. Arguably, one could equate these three states to how landscapes in, for example, large parts of Europe were organized in the Pleistocene, the late Holocene, and the Anthropocene, respectively (Svenning et al. 2016). With a shift from self-regulating to anthropogenic ecosystems, there is an increasing need for a specific human(-mediated) interference to sustain a high diversity (Angelstam 2002, Corlett 2016), because natural processes are degraded, species pools are impoverished, and ecological links are broken.

The human footprint is a cumulative measure of direct and indirect anthropogenic pressure on the environment and is shaped by the duration, type (direct, indirect), extent, and intensity of human disturbances (Venter et al. 2016). Besides the pervasive effect of the current human presence, past activities leave imprints on ecosystems, which persist for decades to centuries after they have occurred (Foster et al. 2003). These land-use legacies have a major influence on current conditions and constrain future responses, thereby codetermining the success of conservation and restoration efforts (Foster et al. 2003, Schweiger et al. 2019). Anthropogenic disturbances further interact with the shape of the ecosystem state curve (Hughes et al. 2013), determining how the ecosystem will respond to an increasing or a declining human footprint (figure 2). Long-lasting and severe human disturbances over an extended area could cause the crossing of certain biotic or abiotic system thresholds (Suding et al. 2004, Hobbs et al. 2009), inducing sudden shifts in ecosystem states (MacDougall et al. 2013). Conversely, biotic (Standish et al. 2008) or abiotic legacies (Foster et al. 2003) may prevent the reverse movement with decreasing human footprint (figure 2c, 2d). This implies that natural conditions 
Box 1. Glossary.

Anthropogenic ecosystems. Ecosystems in which abiotic and biotic conditions have been strongly altered by human activities, often leading to low biodiversity. Anthropogenic biodiverse systems could be spontaneous vegetation on artificial habitats or could be managed for a specific (plant) species composition (e.g., gardens, parks, green roofs).

Ecological restoration. The process of assisting the recovery of damaged, degraded, or destroyed ecosystems (SER 2004). The desired end-state can be defined (e.g., a historical reference state) or open or undefined (Hughes et al. 2012). Restoration can consist of rewilding (e.g., reintroduction of large herbivores) or human intervention actions (e.g., reintroduction of traditional land-use practices, agroforestry).

Intermediate-intensity land management. Land management practices with low(er) levels of anthropogenic inputs and often also lower productivity. Continuation of traditional land management practices (e.g., pastoral systems, haymaking, coppice) or promoted by agri-environment schemes. This type of management is also termed low-intensity or extensive management in the literature.

Nature conservation management. Active human intervention in ecosystem dynamics specifically aimed at preserving or restoring specific species, habitats or ecosystem services. Examples include invasive species management, wildlife-friendly farming, grazing, and mowing management.

Reference ecosystem. Real or notional state of the landscape that serves as a target or benchmark for ecological restoration projects. This reference situation is often a historical state and usually represents a undegraded version of the ecosystem (McDonald et al. 2016).

Rewilding. Restoration aiming to (partially) restore self-sustaining and complex ecosystems through restoring natural ecological processes involved in population, community, and ecosystem dynamics (e.g., predation, herbivory, fire, flooding, scavenging, ecological succession), while minimizing human interventions (Perino et al. 2019). If human activities suppress natural processes, they could be restored through active or passive management actions.

Self-regulating ecosystems. Ecosystems in which natural processes are the main drivers of ecosystem dynamics. Could be (near-) natural ecosystems (i.e., ecosystems without or almost without human impact) or systems in which natural processes are restored.

Seminatural ecosystems. Ecosystems in which species composition and ecosystem dynamics are, to a limited extent, shaped by human activities. The conservation of species and habitats require recurrent intermediate human(-governed) disturbances, because natural processes are (partially) lost. These systems are often specifically managed to maintain a certain ecosystem state. Examples include European haylands and pastoral systems, coppice forests, Japanese Satoyama landscapes, and Australian fire-stick landscapes.

can often not be restored simply by reapplying historical disturbance regimes or reducing anthropogenic pressures (Cava et al. 2018). The shape of the ecosystem state curve affects how ecosystems react to changes in human disturbances or restoration actions (Suding et al. 2004). Therefore, ignoring historical legacies and failing to understand the mechanisms that shaped and sustain the present ecosystem structure and species compositions may lead to inappropriate or unsuccessful conservation actions.

\section{Guiding conservation management decisions}

Insight into the relationship between the human footprint and ecosystem dynamics results in practical guidelines to direct conservation managers and policymakers along the management spectrum. Importantly, we do not consider rewilding and human management to be mutually exclusive. In contrast, some authors put full nonhuman autonomy of the ecosystem forward as an essential end goal of rewilding actions (Prior and Ward 2016). However, the restoration of "the wilderness" ignores the pervasive human footprint on present ecosystems and the infeasibility of completely restoring natural processes in large parts of the world. Some authors therefore suggest using the term wildness instead of wilderness (Perino et al. 2019).
The strict interpretation of rewilding is often not realistic and could result in ignoring the need for human management to maintain certain species and to counteract or limit the effects of global change (Hobbs et al. 2011). The broader rewilding concept of Perino and colleagues (2019) was focused on the general processes more than on a specific compositional state at a given time and encompasses more specific variants such as trophic rewilding (Seddon et al. 2014, Svenning et al. 2016) or passive rewilding (Navarro and Pereira 2012, Schnitzler 2014). Specific management actions to facilitate the transition to a self-regulating state may be needed (Svenning et al. 2016) but depend on the ecological context. Some level of human intervention may, however, still be required after rewilding, because a fully self-regulating state may often be constrained by land-use legacies, land use in adjacent areas, and, in some cases, societal values (boxes 2 and 3 ). On the other hand, human management of biodiverse ecosystems is unlikely to be the most cost-effective solution, given the scale of the biodiversity crisis (Corlett 2016), and is sensitive to shifts in politics and socioeconomic drivers (Fischer et al. 2012).

Traditional conservation managers should look at rewilding to supplement their toolbox in order to create large-scale, robust, adaptive nature. Rather than focusing on specific 
Box 2. Impact of land abandonment and reforestation on biodiversity.

Forest transition theory describes a general temporal pattern in regional forest cover in four distinct stages: a high cover with low deforestation rates, accelerating deforestation, slowing deforestation, and after reaching a minimum, the forest cover slowly starts increasing again (Angelsen 2007). As a range of socioeconomic factors drive the transition, large differences in current stage, minimum forest cover and speed of transition are observed around the world. Some countries or regions are at early stages in this transition and face low (stage 1, e.g., Papua New Guinea) or accelerating deforestation (stage 2, e.g., Brazilian Amazon). Other countries show signs of slowing deforestation (stage 3, e.g., India), indicating the proximity of a turning point (Kanninen et al. 2007, Walker 2012). In many parts of Europe and North America, forest transition took place over the last centuries, with substantial afforestation (stage 4) after the lowest forest cover in the nineteenth century (figure 3a; Angelsen 2007). In some tropical countries, forest transition only recently occurred. In Costa Rica, for example, large-scale deforestation started around 1940 (figure 3a). Forest cover declined rapidly (stages 2-3) from $80 \%$ to $25 \%$ around 1990 before recovering again (stage 4) to more than 50\% in 2015 (Camino Velozo et al. 2015).

Forest transition theory describes temporal trends with little focus on the biological quality of forests. In stage 4, natural forests may continue to decline, with a loss that is more than compensated for by the increase in plantations. The impact of forest expansion on biodiversity is therefore not univocally positive (Rudel et al. 2005). In Europe, two-thirds of the studies indicate negative biodiversity effects of land abandonment and subsequent forest regeneration, whereas positive biodiversity effects dominate the research in Central and South America (Queiroz et al. 2014). Besides the difference in focus of the studies (preabandonment in Europe versus postabandonment in Central and South America), differing land-use histories are at the basis of this contrast.

Human intervention for at least 4000-5000 years has disrupted natural processes and has led to the crossing of certain biotic and abiotic thresholds in Western European landscapes (Dupouey et al. 2002), giving rise to a hysteresis-shaped ecosystem state curve (figure $3 b$ ). Ceasing the human disturbance regimes without restoring the self-regulating state of the landscape (e.g., by reintroducing missing megafauna) could therefore have adverse effects on biodiversity (Queiroz et al. 2014). Generally, the longer the human disturbance regimes have existed and more pervasive they are, the stronger the negative effects of passive land-abandonment could be. In Costa Rica, the decreasing human footprint after land abandonment resulted in a shift toward a more self-regulating state (figure $3 \mathrm{~b}$ ). Natural processes could regain control with recolonization from larger remnants of old-growth forest (Zahawi et al. 2015).

(a) 1
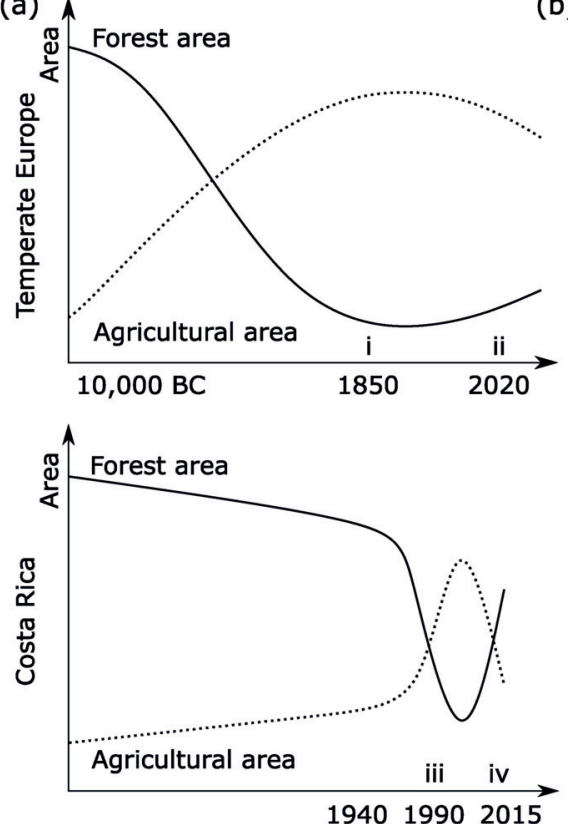

(b) $A$
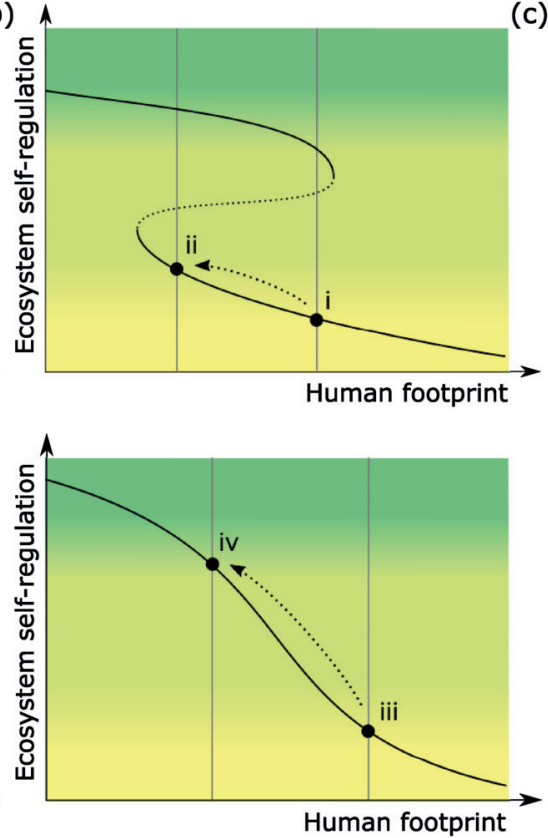

(c) $\mathrm{i}$
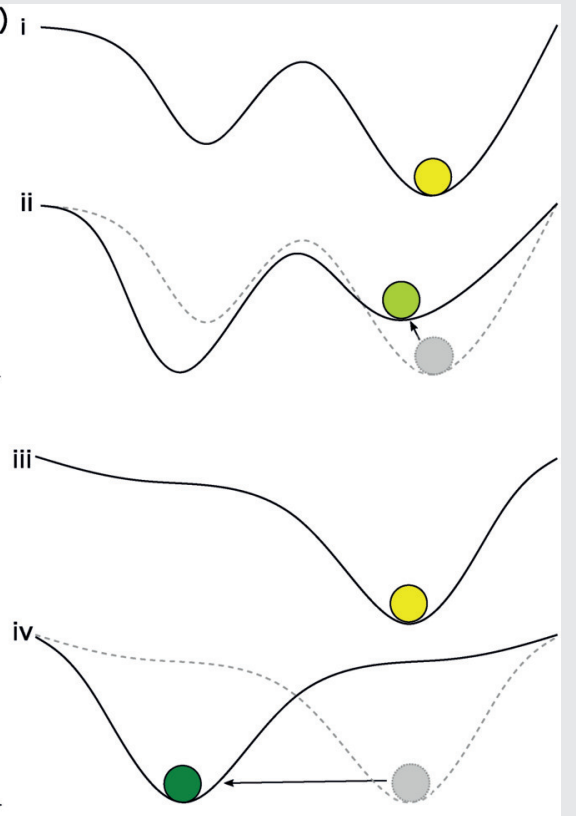

Figure 3. Land abandonment on marginal lands in temperate Europe ( $i$-ii) and on former agricultural land in Costa Rica (iii-iv) depicted on (a) the forest transition curve, (b) the ecosystem state curve and (c) the corresponding stability landscapes that show the stable ecosystem states and their basins of attraction at the different conditions $(i-i v)$. Stable ecosystem states correspond to valleys, with the size depicting its stability. The land-use legacies of the long-term landscape management induced a hysteresis in the ecosystem state curve in parts of temperate Europe, hampering the restoration of self-regulating ecosystems. This partially explains the observed negative effects of landabandonment (Queiroz et al. 2014). The relatively short period of forest transition in Costa Rica and high cover at turning point (Rudel et al. 2005) minimized the human footprint on the landscape and therefore did not induce hysteresis. Source: Partially based on Scheffer and colleagues (2001). 
1. Identify the current state of the ecosystem: self-regulating, seminatural or anthropogenic?

\begin{tabular}{c|c|c}
$\begin{array}{c}\text { Identify and quantify land-use legacies and the } \\
\text { degree of anthropogenic change }\end{array}$ & $\begin{array}{c}\text { Identify and characterize } \\
\text { present biodiversity values }\end{array}$ & $\begin{array}{c}\text { Identify current drivers of biodiversity: natural } \\
\text { processes or human(-mediated) disturbances? }\end{array}$
\end{tabular}

2. Determine management goals and priorities

$\begin{array}{cr}\text { 2. Determine management goals and priorities } \\ \text { Nature conservation with open-endedness approach } & \begin{array}{r}\text { Target-driven nature conservation aiming at specific } \\ \text { landscapes, habitats, species or ecosystem services }\end{array}\end{array}$

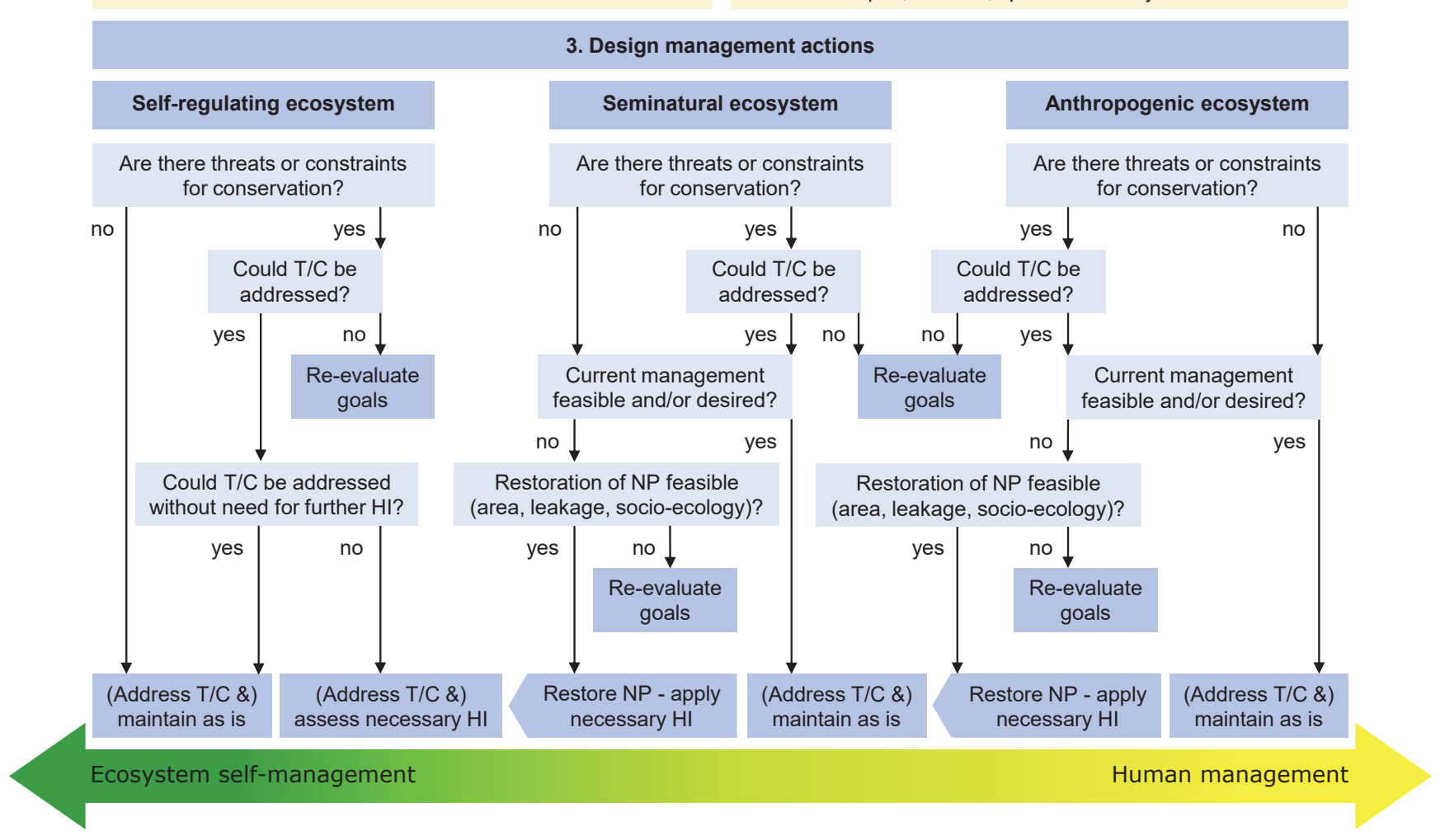

Figure 4. Framework to guide conservation decisions along the management spectrum. The steps are based on the identification of the ecosystem state (self-regulating, seminatural or anthropogenic) and human footprint including land-use legacies. In the third step of the framework, the effects of rewilding actions (i.e., restoration of natural processes) on the ecosystem state are uncertain, indicated by an arrow directed toward the ecosystem self-management end of the management continuum. Abbreviations: HI, Human intervention; NP, Natural processes; T/C, threats and constraints.

species or habitats as in traditional conservation, rewilding has a more functional focus. The aim to move the ecosystem on the management continuum toward ecosystem self-management (figure 1) sets it apart from other forms of conservation or restoration projects. The restoration of natural processes could enhance the stability of ecosystems in the face of rapid environmental change (Mausolf et al. 2018). Therefore, we advocate for rewilding where possible and human intervention where needed. We identified three steps in the process of making conservation management decisions: (1) Ecosystem inventory and the identification of the ecosystem state, (2) the determination of conservation goals, and (3) the design of concrete management actions (figure 4). Reiterations of the different steps are possible or could even be recommended.
Conservation goals and trajectories toward those goals are, in the first place, constrained by the state of the ecosystem. Understanding the processes that shape and have shaped the ecosystem is important for the success of management actions. The framework does not rely on the identification of a specific natural historical reference situation or the division among historical, hybrid, and novel ecosystems (Hobbs et al. 2014), which allows us to avoid baseline discussions (Murcia et al. 2014). However, the historical perspective aids the interpretation of the landscape. Knowledge about past states is invaluable to reveal ecosystem function and structure before the onset of human disturbance and to identify past trajectories of change (Sandom et al. 2014). Therefore, knowledge about past land-use should be used not to restore previous conditions 
Box 3. Informing conservation management decisions.

Insight into the ecosystem state curve can be used to understand the success and failure of conservation and restoration projects and to develop future programs. In this box, we apply the proposed framework to understand the outcome of three restoration projects. The Danube delta (case 1), on the border between Romania and Ukraine, is one of the largest deltas in Europe. Human interventions since the second half of the nineteenth century (e.g., channelization, construction of dams, land reclamation) completely altered the floodplain dynamics and transformed the delta from a natural to a human-controlled system (Ebert et al. 2009). After enlisting as a UNESCO World Heritage site in 1991, large-scale restoration works successfully restored river dynamics, resulting in the regeneration of vegetation, increased diversity, and enhanced water quality (figure 5a; Ebert et al. 2009). Since 2015, Rewilding Europe has been introducing free-roaming large grazers to create a mosaic landscape with new opportunities for other species. The rewilding efforts are paying off, with the comeback or increasing populations of some remarkable species, such as the beaver, the golden jackal, and the white-tailed eagle (Rewiding Europe 2019).

Calcareous grasslands (case 2) are among the most plant-species-rich habitats in Europe and are shaped or maintained by millennia of extensive cultivation and grazing (Poschlod and WallisDeVries 2002, Feurdean et al. 2018), although the large majority of the constituent species are much older than these human land uses. Albeit conserving a unique habitat for many species, these anthropogenic activities excluded other naturally occurring species, such as wild megafauna (Turvey and Fritz 2011). Since the end of the nineteenth century, land-use intensification has induced the abandonment of traditional practices on marginal lands (Poschlod and WallisDeVries 2002). The reduced human footprint resulted in landscape closure because of shrub encroachment and afforestation (figure 5b). Rare and endemic species of open habitats declined following the decrease in landscape heterogeneity. Since 1992, calcareous grasslands are protected by the European Habitats directive. Restoration projects that were focused on reapplying human disturbances by shrub clearance and reinstallation of grazing management generally showed positive effects on plant diversity (Maccherini and Santi 2012).

(a)
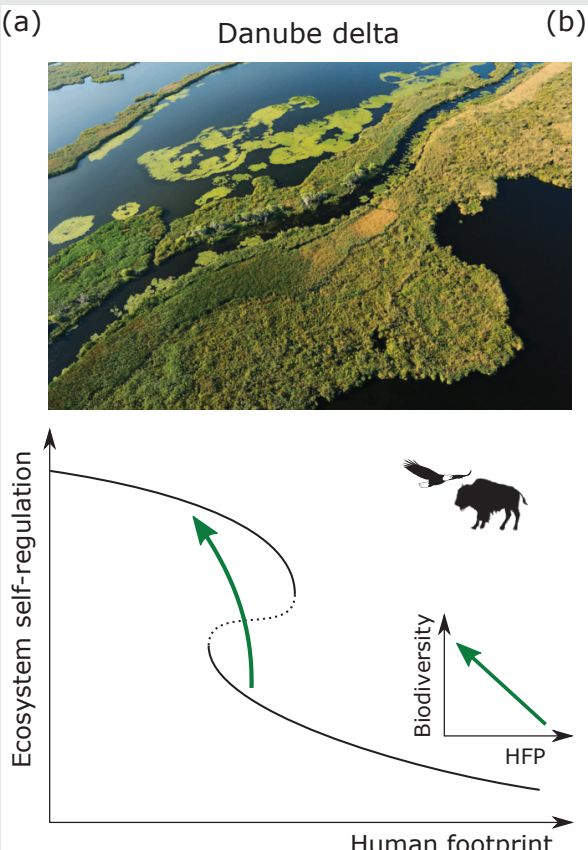

(b)
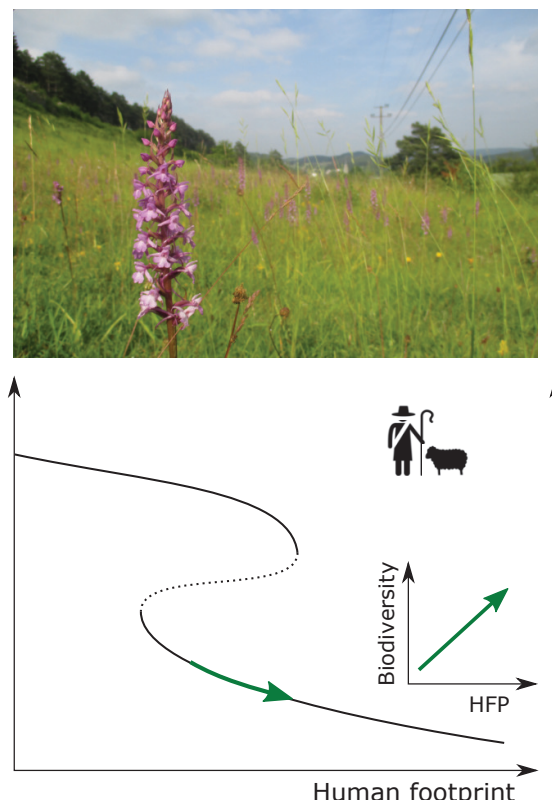

(c)
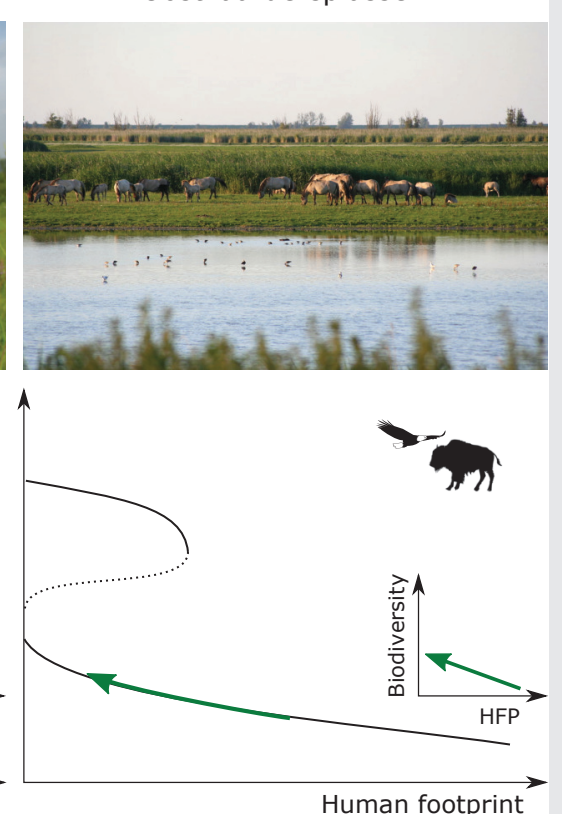

Figure 5. Trajectory of three examples of restoration programs on the ecosystem state curve with the relationship between human footprint (HFP) and biodiversity. Only relative changes in biodiversity within a project are shown. $A$ comparison between projects is not valid. (a) Rewilding in the Danube Delta, Romania, with the successful restoration of river dynamics and species introductions. Photograph: Rewilding Europe. (b) The restoration of overgrown calcareous grassland in many cases entails the mimicking or reapplication of the traditional farming practices and, therefore, the increase of the human footprint. A population of fragrant orchids (Gymnadenia conopsea) reappeared on a restored grassland in the Viroin region, Belgium Photograph: Kenny Helsen. (c) Trophic rewilding with Konik horses in the Oostvaardersplassen, in the Netherlands. The hysteresis resulted from ecological and societal constraints and led to a different ecological outcome (with lower biodiversity gains) than expected. Photograph: Eva-Maria Kintzel and Ivo Van Stokkum (CC-BY-SA-3.0,2.5,2.0,1.0). 
Box 3. Continued.

The Dutch Oostvaardersplassen (case 3), situated on land reclaimed from Lake Ijssel in 1968, is the forerunner of the European rewilding movement (Smit et al. 2015). In the 1980s and 1990s, large grazers were introduced into a fenced area with the aim of restoring the open wood-pasture primeval landscape (Vera 2000). Besides the discussion about possible ecological constraints, the socioecological context of being located in a highly urbanized region poses societal constraints and induces strong hysteresis (figure $5 \mathrm{c}$ ). The large impact of recent periods of scarcity on animal populations provoked protests about animal welfare and a fierce debate about the management, even among biologists (Lorimer et al. 2015). In the summer of 2018, the province abandoned the no-intervention rewilding strategy and decided to control herbivore populations.

(history as a template) but to identify constraints and to frame future management efforts (history as a guide; Higgs et al. 2014).

For example, knowledge about the evolutionary baseline serves as a guideline for restoring natural processes in rewilding projects. This baseline isn't a specific point in time but the general ecosystem conditions over the evolutionary time scales during which species have evolved and persisted. Land-use legacies and the degree of anthropogenic change can be identified by studying site history and the pressure of current human activities. For Europe, a hemeroby map (i.e., the degree of human influence; Sukopp and Hejn 1990) of the landscape based on land cover, nitrogen input, and livestock density is available for developing conservation strategies (JRC 2012). In addition, the Human Footprint project provides a measure of human influence with global coverage considering eight human pressures (Venter et al. 2016). Ceaușu and colleagues (2015) have already used a similar approach to map opportunities for rewilding in Europe. However, these maps only take current pressures into account and leave out land-use legacies. Opposite to the human footprint and hemeroby is the biodiversity intactness index of the system, a measure of how intact the ecosystem is relative to its presumed premodern state (Scholes and Biggs 2005). The PREDICTS project developed a global data set of this index (Newbold et al. 2016). Although the availability of spatially explicit data about land-use history is growing, it may not have reached the required detail and resolution to inform local decisionmaking. However, nowadays, several approaches are at our disposal to reconstruct site history, ranging from archeology (Dupouey et al. 2002, Foster et al. 2003) and historical maps (Foster 2002) to soil cores, pollen diagrams, and fossils (Svenning 2002).

Apart from knowledge of past human activities, it is as important to look at the resulting biodiversity patterns today. The rareness or uniqueness of species, together with their ecological requirements, could have important management implications. Field surveys are still the most accurate way to map current biodiversity values, but large-scale online databases such as GBIF (Global Biodiversity Information Facility) and citizen science projects are promising tools to provide detailed species occurrence data at larger geographic scales (Dickinson et al. 2012). All this information, together with the nature of the prevailing disturbances regimes, can inform managers about the shape of the ecosystem state curve and the position of the specific ecosystem on this curve (figure 2).

Conservation is about values (Meijaard and Sheil 2011), which determine how we perceive nature and which landscapes we find important. The decision on conservation goals in the second step of the framework is therefore, besides being framed by the ecological context, also a societal choice (Berkes et al. 2000). Being embedded within society nature conservation projects need to take the socioecological context into account (Perino et al. 2019). Socioeconomic trends such as land-use dynamics could further provide opportunities for biodiversity conservation (Pereira and Navarro 2015) but could also pose eminent threats (e.g., calcareous grasslands in box 3). Strict legal requirements call for target-driven conservation or restoration. The protection of endangered species and the control of invasive species urge the adoption of species-specific management plans. The European Birds and Habitats Directives, for example, obliges its member states to protect more than 1400 European species, as well as 230 habitat types. In addition, the cultural value of the landscape can be subject of legislation, such as UNESCO World Heritage sites. In most cases, the need to achieve specific targets often urges active intervention. Conversely, an open-ended approach to conservation and restoration acknowledges the inherent dynamic behavior of ecosystems and sets a direction of change-rather than a specific state-as the desired outcome (Hughes et al. 2012). Without the predicament of a targeted ecological outcome, human intervention can be minimized, and natural processes could take over. Therefore, factors that call for open-endedness, such as climate change, remoteness, large project areas, and high management costs, also favor rewilding (Hughes et al. 2012).

In step 3, the characterization of threats and constraints to reach the goals will further determine the necessary and feasible management trajectory. Also at this stage, the socioecological context continues to influence the conservation process. Human perception of and preference for a given landscape influences the acceptance of management actions and ecosystem change (e.g., the Oostvaardersplassen in box 3). Management costs are a practical constraint and are often positively correlated with the surface area and 
remoteness of the ecosystem but are also strongly affected by the national and regional labor market.

The size of the system is further important when considering the restoration of natural processes (Kuemmerle et al. 2010). The smaller the considered ecosystem, the more important the role of the surrounding area becomes. The intensity of the surrounding land-use increases the risk of inward leakage of tourism, pollution, nutrients, or invasive species (Corlett 2016), which often increase the need for recurring management.

After the threats and constraints have been addressed, an assessment must be made about the position of the ecosystem on the management spectrum and the level of human intervention that is still required. Disturbance-dependent species, for example, may need continuing human intervention when natural disturbance regimes cannot be restored (Scott et al. 2005). The actual design of specific management actions (step 3) is very context dependent and is left to the dedicated literature (e.g., Sutherland et al. 2015).

\section{Conclusions}

Despite increasing conservation efforts, we are not succeeding in slowing down the rates of biodiversity loss. We urgently need solutions that fit the scale and pervasiveness of the problem. Although the division is not strict, two largely opposing views form the basis of the scientific literature on nature conservation: Rewilding proponents aim at restoring self-regulating ecosystems, whereas traditional conservationists argue that human intervention is needed to maintain biodiversity. We have shown that rewilding and human intervention are not mutually exclusive but are, instead, complementary management strategies. Practices from the two paradigms should be combined to tackle the biodiversity crisis. We presented a framework to guide decisions along the spectrum from human intervention to ecosystem self-management, allowing better strategic conservation management choices.

Global change has altered ecosystems and will continue to alter them. Current solutions may not work in the future (Brooks et al. 2006, Ordonez et al. 2016). Rewilding is focused on the general processes more than on a specific compositional state at a given point in time and, as a consequence, could offer a solution to the unpredictability of future ecosystem responses to changing conditions. However, because of land-use legacies and the increasing, pervasive human footprint, the restoration of self-regulating ecosystems is not always feasible. This is especially true in cases of threatened species with small, very sensitive populations-notably, if they are confined to small (semi) natural areas with specific ecosystem conditions.

There may, of course, also be cases in which rewilding is not wanted for societal reasons-for example, because of the protection of certain cultural heritage. Moreover, not all rewilding actions completely remove the need for human actions. Therefore, our framework's basis is rewilding where possible, human intervention where needed.
Mutual learning can improve the implementation of both practices considerably. Although the focus has shifted from safeguarding species or habitats to the restoration of natural processes to achieve self-managing ecosystems, most of the rewilding tools are not new (Hayward et al. 2019). Therefore, rewilding research has much to learn from related fields, such as reintroduction biology, restoration ecology, and traditional conservation science, along with basic ecology. On the other hand, better insight into natural processes (including disturbance dynamics) can be used to improve and better aim human intervention. We therefore call for a joint research agenda, instead of a focus only on one end of the management spectrum.

\section{Acknowledgements}

We thank the two anonymous reviewers for their valuable comments and suggestions. JCS considers this work a contribution to his VILLUM Investigator project "Biodiversity Dynamics in a Changing World" funded by VILLUM FONDEN (grant no. 16549) and to his Carlsberg Foundation Semper Ardens project MegaPast2Future (grant no. CF16-0005).

\section{References cited}

Angelsen A. 2007. Forest Cover Change in Space and Time: Combining the von Thünen and Forest Transition Theories. World Bank.

Angelstam P. 2002. Reconciling the linkages of land management with natural disturbance regimes to maintain forest biodiversity. Pages 193-226 in Bissonette JA, Storch I, eds. Landscape Ecology and Resource Management: Linking Theory with Practice. Island Press.

Berkes F, Folke C, Colding J. 2000. Linking Social and Ecological Systems: Management Practices and Social Mechanisms for Building Resilience. Cambridge University Press.

Bird RB, Nimmo D. 2018. Restore the lost ecological functions of people. Nature Ecology and Evolution 2: 1050.

Boitani L, Sutherland WJ. 2015. Introduction. Conservation Biology 29: 975-977. Brooks TM, Mittermeier RA, Fonseca GAB da, Gerlach J, Hoffmann M, Lamoreux JF, Mittermeier CG, Pilgrim JD, Rodrigues AS. 2006. Global biodiversity conservation priorities. Science 313: 58-61.

De Camino Velozo R, Villalobos R, Morales Aymerich JP. 2015. Costa Rica Case Study: Prepared for FAO as Part of the State of the World's Forests 2016 (SOFO). Food and Agricultural Organization of the United Nations

Cava MGB, Pilon NAL, Ribeiro MC, Durigan G. 2018. Abandoned pastures cannot spontaneously recover the attributes of old-growth savannas. Journal of Applied Ecology 55: 1164-1172.

Ceaușu S, Hofmann M, Navarro LM, Carver S, Verburg PH, Pereira HM. 2015. Mapping opportunities and challenges for rewilding in Europe. Conservation Biology 29: 1017-1027.

Corlett RT. 2016. Restoration, reintroduction, and rewilding in a changing world. Trends in Ecology and Evolution 31: 453-462.

Dickinson JL, Shirk J, Bonter D, Bonney R, Crain RL, Martin L, Phillips T, Purcell K. 2012. The current state of citizen science as a tool for ecological research and public engagement. Frontiers in Ecology and the Environment 10: 291-297.

Dupouey J-L, Dambrine E, Laffite J-D, Moares C. 2002. Irreversible impact of past land use on forest soils and biodiversity. Ecology 83: 2978-2984.

Ebert S, Hulea O, Strobel D. 2009. Floodplain restoration along the lower Danube: A climate change adaptation case study. Climate and Development 1: 212-219.

Fernández N, Navarro LM, Pereira HM. 2017. Rewilding: A call for boosting ecological complexity in conservation. Conservation Letters 10: 276-278. 
Feurdean A, Ruprecht E, Molnár Z, Hutchinsond SM, Hickler T 2018 Biodiversity-rich European grasslands: Ancient, forgotten ecosystems. Biological Conservation 228: 224-232.

Fischer J, Hartel T, Kuemmerle T. 2012. Conservation policy in traditional farming landscapes. Conservation Letters 5: 167-175.

Foster DR. 2002. Insights from historical geography to ecology and conservation: Lessons from the New England landscape. Journal of Biogeography 29: 1269-1275.

Foster D, Swanson F, Aber J, Burke I, Brokaw N, Tilman D, Knapp A. 2003. The importance of land-use legacies to ecology and conservation. BioScience 53: 77-88.

Halada L, Evans D, Romão C, Petersen J. 2011. Which habitats of European importance depend on agricultural practices? Biodiversity and Conservation 20: 2365-2378.

Hayward MW, et al. 2019. Reintroducing rewilding to restoration: Rejecting the search for novelty. Biological Conservation 233: 255-259.

Higgs E, Falk DA, Guerrini A, Hall M, Harris J, Hobbs RJ, Jackson ST, Rhemtulla JM, Throop W. 2014. The changing role of history in restoration ecology. Frontiers in Ecology and the Environment 12: 499-506.

Hobbs RJ, Hallett LM, Ehrlich PR, Mooney HA. 2011. Intervention ecology: Applying ecological science in the twenty-first century. BioScience 61: $442-450$.

Hobbs RJ, et al. 2014. Managing the whole landscape: Historical, hybrid, and novel ecosystems. Frontiers in Ecology and the Environment 12: 557-564.

Hobbs RJ, Higgs E, Harris JA. 2009. Novel ecosystems: Implications for conservation and restoration. Trends in Ecology and Evolution 24: 599-605.

Hughes FMR, Adams WM, Stroh PA. 2012. When is open-endedness desirable in restoration projects? Restoration Ecology 20: 291-295.

Hughes TP, Carpenter S, Rockström J, Scheffer M, Walker B. 2013. Multiscale regime shifts and planetary boundaries. Trends in Ecology and Evolution 28: 389-395.

[JRC] Joint Research Centre, European Commission. 2012. Degree of hemeroby (naturalness) of the overall landscape in EU countries (19962005). Ecoclimax. www.ecoclimax.com/2017/09/degree-of-hemerobynaturalness-of.html.

Kanninen M, Murdiyarso D, Seymour F, Angelsen A, Wunder S, German L. 2007. Do Trees Grow on Money? The Implications of Deforestation Research for Policies to Promote REDD. Cifor.

Kuemmerle T, Perzanowski K, Chaskoversuskyy O, Ostapowicz K, Halada L, Bashta HT, Kruhlov I, Hostert P, Waller DM, Radeloff VC. 2010. European bison habitat in the Carpathian Mountains. Biological Conservation 143: 908-916.

Lorimer J, Sandom C, Jepson P, Doughty C, Barua M, Kirby KJ. 2015. Rewilding: Science, practice, and politics. Annual Review of Environment and Resources 40: 39-62.

Maccherini S, Santi E. 2012. Long-term experimental restoration in a calcareous grassland: Identifying the most effective restoration strategies. Biological Conservation 146: 123-135.

MacDougall AS, McCann KS, Gellner G, Turkington R. 2013. Diversity loss with persistent human disturbance increases vulnerability to ecosystem collapse. Nature 494: 86.

Mausolf K, Wilm P, Härdtle W, Jansen K, Schuldt B, Sturm K, Oheimb G, Hertel D, Leuschner, C, Fichtner A. 2018. Higher drought sensitivity of radial growth of European beech in managed than in unmanaged forests. Science of The Total Environment 642: 1201-1208.

McDonald T, Jonson J, Dixon KW. 2016. National standards for the practice of ecological restoration in Australia. Restoration Ecology 24: S4-32.

Meijaard E, Sheil D. 2011. A modest proposal for wealthy countries to reforest their land for the common good. Biotropica 43: 524-528.

Murcia C, Aronson J, Kattan GH, Moreno-Mateos D, Dixon K, Simberloff D. 2014. A critique of the "novel ecosystem" concept. Trends in Ecology and Evolution 29: 548-553.

Navarro LM, Pereira HM. 2012. Rewilding abandoned landscapes in Europe. Ecosystems 15: 900-912.
Newbold T, et al. 2016. Has land use pushed terrestrial biodiversity beyond the planetary boundary? A global assessment. Science 353: 288-291.

Nogués-Bravo D, Simberloff D, Rahbek C, Sanders NJ. 2016. Rewilding is the new Pandora's box in conservation. Current Biology 26: R87-R91.

Normile D. 2016. Nature from nurture. Science 351: 908-910.

Ordonez A, Williams JW, Svenning JC. 2016. Mapping climatic mechanisms likely to favour the emergence of novel communities. Nature Climate Change 6: 1104.

Pereira HM, Navarro LM. 2015. Rewilding European Landscapes. Springer.

Perino A, et al. 2019. Rewilding complex ecosystems. Science 364: eaav5570.

Poschlod P, WallisDeVries MF. 2002. The historical and socioeconomic perspective of calcareous grasslands: Lessons from the distant and recent past. Biological Conservation 104: 361-376.

Prior J, Ward KJ. 2016. Rethinking rewilding: A response to Jørgensen. Geoforum 69: 132-135.

Queiroz C, Beilin R, Folke C, Lindborg R. 2014. Farmland abandonment: Threat or opportunity for biodiversity conservation? A global review. Frontiers in Ecology and the Environment 12: 288-296.

Rewiding Europe. 2019. Danube Delta: Europe's Unrivalled Wetland. Rewilding Europe. https://rewildingeurope.com/areas/danube-delta

Rudel TK, Coomes OT, Moran E, Achard F, Angelsen A, Xu J, Lambin E. 2005. Forest transitions: Towards a global understanding of land use change. Global Environmental Change 15: 23-31.

Sandom CJ, Ejrnæs R, Hansen MDD, Svenning J-C. 2014. High herbivore density associated with vegetation diversity in interglacial ecosystems. Proceedings of the National Academy of Sciences 111: 4162-4167.

Scheffer M, Carpenter S, Foley JA, Folke C, Walker B. 2001. Catastrophic shifts in ecosystems. Nature 413: 591-596.

Schnitzler A. 2014. Towards a new European wilderness: Embracing unmanaged forest growth and the decolonisation of nature. Landscape and Urban Planning 126: 74-80.

Scholes RJ, Biggs R. 2005. A biodiversity intactness index. Nature 434: 45.

Schweiger AH, Boulangeat I, Conradi T, Davis M, Svenning JC. 2019. The importance of ecological memory for trophic rewilding as an ecosystem restoration approach. Biological Reviews 94: 1-15.

Scott JM, Goble DD, Wiens JA, Wilcove DS, Bean M, Male T. 2005. Recovery of imperiled species under the Endangered Species Act: The need for a new approach. Frontiers in Ecology and the Environment 3: 383-389.

Seddon PJ, Griffiths CJ, Soorae PS, Armstrong DP. 2014. Reversing defaunation: Restoring species in a changing world. Science 345: 406-412.

[SER] Society for Ecological Restoration International Science and Policy Working Group. 2004. The SER International Primer on Ecological Restoration. SER.

Smit C, Ruifrok JL, Klink R van, Olff H. 2015. Rewilding with large herbivores: The importance of grazing refuges for sapling establishment and wood-pasture formation. Biological Conservation 182: 134-142.

Standish RJ, Cramer VA, Hobbs RJ. 2008. Land-use legacy and the persistence of invasive Avena barbata on abandoned farmland. Journal of Applied Ecology 45: 1576-1583.

Suding KN, Gross KL, Houseman GR. 2004. Alternative states and positive feedbacks in restoration ecology. Trends in Ecology and Evolution 19: $46-53$.

Suding KN, Hobbs RJ. 2009. Threshold models in restoration and conservation: A developing framework. Trends in Ecology and Evolution 24: 271-279.

Sukopp H, Hejn S. 1990. Urban Ecology: Plants And Plant Communities In Urban Environments. Balogh Scientific.

Sutherland WJ. 2002. Conservation biology: Openness in management. Nature 418: 834. 
Sutherland WJ, Dicks L V, Ockendon N, Smith RK. 2015. What Works in Conservation. Open Book Publishers.

Svenning J-C. 2002. A review of natural vegetation openness in northwestern Europe. Biological Conservation 104: 133-148.

Svenning JC, et al. 2016. Science for a wilder Anthropocene: Synthesis and future directions for trophic rewilding research. Proceedings of the National Academy of Sciences 113: 898-906.

Turvey ST, Fritz SA. 2011. The ghosts of mammals past: Biological and geographical patterns of global mammalian extinction across the Holocene. Philosophical Transactions of the Royal Society B 366: 2564-2576.

Venter O, et al. 2016. Sixteen years of change in the global terrestrial human footprint and implications for biodiversity conservation. Nature Communications 7: 12558.
Vera FWM. 2000. Grazing ecology and forest history. CABI.

Walker R. 2012. The scale of forest transition: Amazonia and the Atlantic forests of Brazil. Applied Geography 32: 12-20.

Zahawi RA, Duran G, Kormann U. 2015. Sixty-seven years of land-use change in southern Costa Rica. PLOS ONE 10 (art. e0143554).

Koenraad Van Meerbeek (koenraad.vanmeerbeek@kuleuven.be) is an assistant professor and Bart Muys is a professor in the Department of Earth and Environmental Sciences at KU Leuven, in Leuven, Belgium. Jens-Christian Svenning is a professor and Simon D. Schowanek is a PhD researcher in the Department of Bioscience and the Center for Biodiversity Dynamics in a Changing World (BIOCHANGE), at Aarhus University, in Aarhus, Denmark. 